\title{
Heavy metals removal from aqueous solution through micellar enhanced ultrafiltration: A review
}

\author{
Muhammad Yaqub, Seung Hwan Lee ${ }^{\dagger}$ \\ Department of Environmental Engineering, Kumoh National Institute of Technology, Gumi 39177, Republic of Korea
}

\begin{abstract}
Micellar-enhanced ultrafiltration (MEUF) is a surfactant-based separation technique and has been investigated for the removal of heavy metals from wastewater. The performance of heavy metals removal from wastewater through MEUF relies on membrane characteristics, surfactant properties, various operational parameters including operating pressure, surfactant and heavy metal concentration, $\mathrm{pH}$ of the solution, temperature, and presence of dissolved solutes and salts. This study presents an overview of literature related to MEUF with respect to the all significant parameters including membranes, surfactants, operating conditions and MEUF hybrid processes. Moreover, this study illustrates that MEUF is an adaptable technique in various applications. Nowadays water contamination caused by heavy metals has become a serious concern around the globe. MEUF is a significant separation technique in wastewater treatment that should be acknowledged, for the reason that removal of heavy metals contamination even at lower concentrations becomes achievable, which is evidently made known in the presented review. Hybrid processes presented the better results as compared to MEUF. Future studies are required to continue the experimental work with various combinations of surfactant and heavy metals, and to investigate for the treatment of concentrated solutions, as well as for real industrial wastewater.
\end{abstract}

Keywords: Activated carbon fiber, Heavy metals, Membrane, Micellar enhanced ultrafiltration, Surfactant

\section{Introduction}

Heavy metals have been noticed as a significant pollutant in wastewater which leads to serious health problems and damages the natural water sources [1]. Various techniques were employed to remove targeted heavy metals, including precipitation, adsorption [2, 3] bio-sorption [4], ion exchange [5] and reverse osmosis [6]. In the last two decades micellar-enhanced ultrafiltration (MEUF) as a surfactant-based separation technique has achieved great attention for heavy metals removal from aqueous solution. This technique combines the high removal efficiency of reverse osmosis (RO) and the high permeate flux of ultrafiltration. In this technique molecular weight of pollutant molecules is enlarged through application of surfactants. It occurs above critical micelles concentration (CMC), at which surfactant monomers agglomerate into micelles, having large size than pore size of ultrafiltration membranes. The micelles can be rejected by ultrafiltration membrane while the surfactant monomers can pass through [7]. The main advantage of MEUF over conventional ultrafiltration is that even at lower concentrations molecules usually too small to be rejected by ultrafiltration membranes can bind to the micelles because of ionic or hydrophobic interactions and subsequently separated together with them in the ultrafiltration step. The performance of complex MEUF process depends on a variety of parameters such as membrane characteristics, surfactant properties, operating conditions, and dissolved solutes. Many studies have been carried out to investigate the performance of MEUF and how it was influenced by aforementioned parameters. Commonly, there are no universal experimental conditions that can be applied to MEUF experiments. In fact, experimental parameters have to be selected based on the individual system and this review gives an overview of MEUF efficiency with respect to selected operational parameters. Previous studies have been encapsulated with respect to membrane characteristics, surfactant properties, and operational parameters by using single or mixed micellar solutions, dissolved solutes and further applications.
This is an Open Access article distributed under the terms of the Creative Commons Attribution Non-Commercial License (http://creativecommons.org/licenses/by-nc/3.0/) which permits unrestricted non-commercial use, distribution, and reproduction in any medium, provided the original work is properly cited.
Received July 24, 2018 Accepted November 23, 2018

${ }^{\dagger}$ Corresponding author

Email: dlee@kumoh.ac.kr

Tel: +82-54-478-7632 Fax: +82-54-478-7629

Copyright (C) 2019 Korean Society of Environmental Engineers 


\section{Micellar Enhanced Ultrafiltration (MEUF)}

MEUF is a separation technique used for the removal of heavy metals, organic or inorganic pollutants from wastewater streams. In this technique surfactant is added in to an aqueous stream to form micelles above their CMC which is the minimum concentration of surfactant at which micelles formation starts. The aggregated surfactant monomers known as micelles and metal ions tend to be soluble by these micelles due to electrostatic or Van der Waals force. Afterwards, an appropriate molecular weight cut-off (MWCO) ultrafiltration membrane is used for filtration of the micelles solution which is capable to retains the micelles containing pollutants [8]. MEUF separation technique is considered due to its low operating cost, high permeate flux and better removal efficiency which is the combination of high selectivity of the reverse osmosis and high flux of ultrafiltration [9]. A schematic diagram of MEUF process is shown in Fig. 1.

\subsection{MEUF Parameters and Their Selection}

The performance of MEUF depends upon material selection of ultrafiltration membranes and other characteristics, properties of surfactants, operating parameters, and dissolved ions in the solution as shown in Fig. 2. In the following sections, these parameters and their influence on MEUF performance are summarized.

\subsubsection{Surfactants}

The literature studies presented $23 \%$ of $\mathrm{Cu}^{2+}$ removal [10] and $15 \% \mathrm{CrO}_{4}{ }^{2-}$ by using PAN membrane [11], 24\% rejection of $\mathrm{Cu}^{2+}$ and $\mathrm{Co}^{2+}$ when PES membrane was used [12], $4 \% \mathrm{Ni}^{2+}$ and $5 \%$ $\mathrm{Zn}^{2+}$ was retained by regenerated cellulose membranes [13] in the absence of surfactants. These results proved the importance of surfactant application in MEUF process and a suitable surfactant selection is one of the main factors considered in this separation technique. The CMC expresses micelles formation which is measured on the basis of change of physical properties of the solution most commonly electrical conductivity and surface tension. Various available surfactants are classified into four main types; anionic, cationic, nonionic, and amphoteric.

Mostly ionic surfactants are preferred in MEUF process due to their ion-pair complex formation ability with opposite charged ions for the removal of metal ions from aqueous solution through ultrafiltration. The addition of the nonionic surfactant decreases the CMC of ionic surfactants significantly to form mixed-micellar solutions. Some surfactants having properties of both ionic and nonionic surfactants are attractive due to their low CMC. These surfactants are very helpful for the metal removal and surfactants recovery as well because at high $\mathrm{pH}$, the metal ions can bind to the micelles and can be released later by lowering the $\mathrm{pH}$ value [14]. Another group of surfactants with low CMC is twin-headed cationic surfactants [7]. The characteristics of some selected surfactants are presented in Table S1.

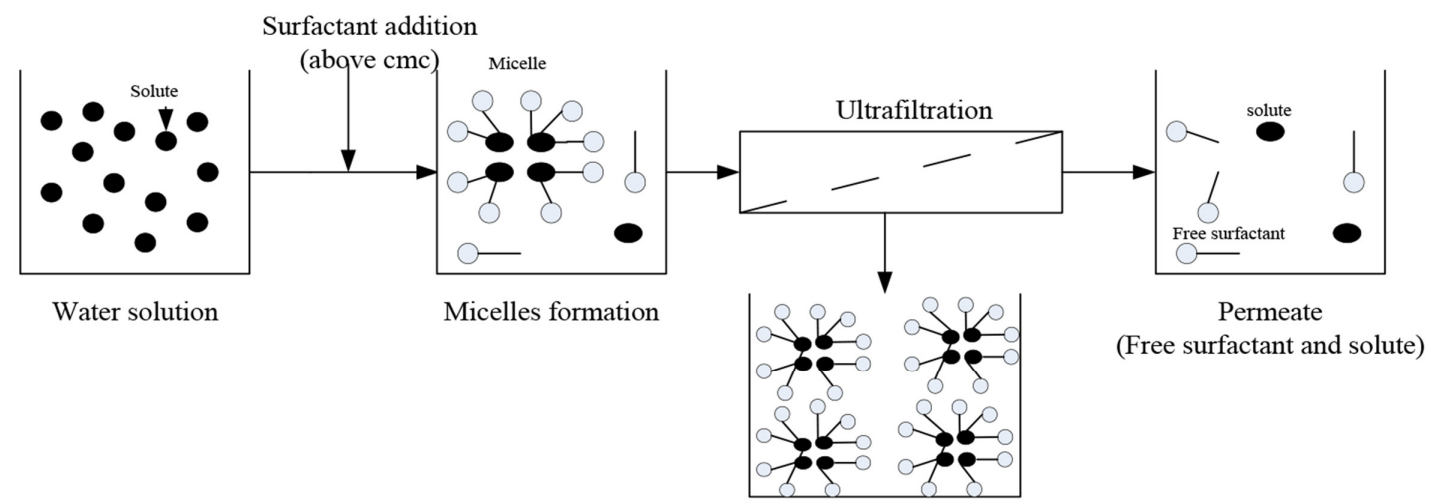

Fig. 1. MEUF process schematic diagram.

Retentate with loaded micelles

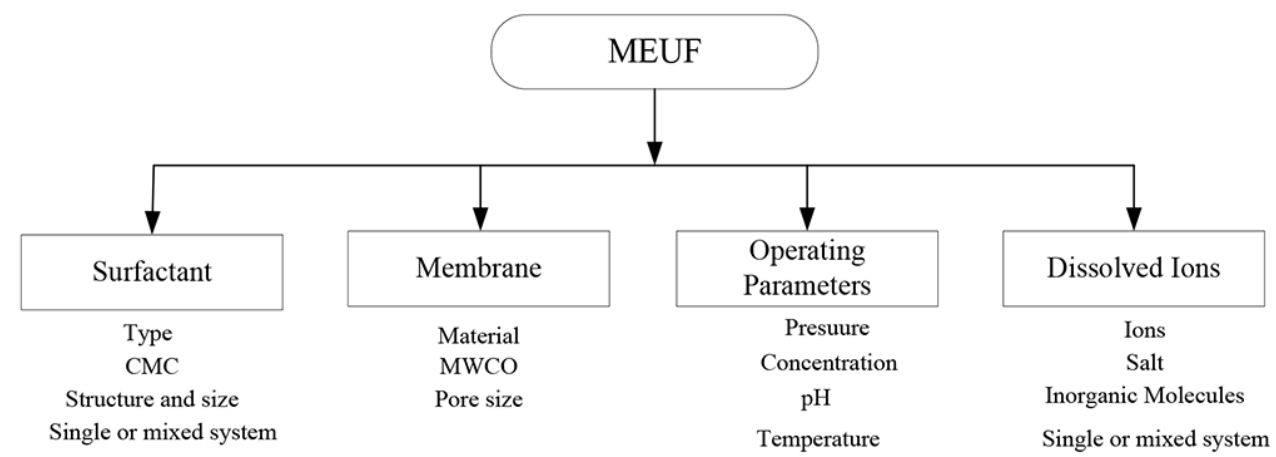

Fig. 2. MEUF operating parameters block diagram. 
Table 1. Filtration of Selected Surfactant Solutions

\begin{tabular}{|c|c|c|c|}
\hline Surfactant & Membrane & Parameter studied & References \\
\hline SDS & $\mathrm{ZrO}_{2} @ \mathrm{C}, \mathrm{RC}, \mathrm{PS}, \mathrm{CA}, \mathrm{PA}, \mathrm{PES}$ & S, Temp, FC \& TMP & [21-23] \\
\hline CTAB & $\mathrm{ZrO}_{2} @ \mathrm{C}$ & S, Temp, Feed flow & {$[20]$} \\
\hline TX-100 & RC, PES & S, Temp, MWCO & [24-26] \\
\hline SDS, SDBS, Tween 80 (TW-80) & RC & HLB, Salt, Additives & [22] \\
\hline SDS, CTAB, APG & $\mathrm{RC}$ & Temp & [23] \\
\hline SDS, CTAB, TX-100 & RC, PES & S, MWCO, Additives & [27] \\
\hline CTAB, CPC, SDS & RC, PS & Salt & [24] \\
\hline
\end{tabular}

$\mathrm{S}=$ surfactant concentration, Temp $=$ temperature, $\mathrm{MWCO}=$ molecular weight cut-off, HLB = hydrophilic-lipophilic balance

Table 2. Metal lons Removal with Anionic/Nonionic Mixed Micellar Solutions

\begin{tabular}{|c|c|c|c|c|c|}
\hline Metal ions & $\mathbf{S}$ & Nonionic S & M/pore size (kDa) & R (\%) & References \\
\hline $\mathrm{Cd}^{2+}$ & SDS & TX-100, Brij35 & $\mathrm{C} / 10, \mathrm{PS} / 6, \mathrm{PS} / 6-10$ & $98,96.8,96$ & [33-35] \\
\hline $\mathrm{Ni}^{2+}$ & SDS & TW-80 & $\mathrm{PS} / 6$ & 91.7 & {$[7]$} \\
\hline $\mathrm{Ni}^{2+}$ & SDS & TX-114, TX-100 & $\mathrm{PS} / 5$ & 98, 99 & [28] \\
\hline $\mathrm{Ni}^{2+}$ & SDS & Brij35, TX-405 & $\mathrm{PS} / 5$ & 96, 95 & [28] \\
\hline $\mathrm{Cu}^{2+}$ & SDS & TX-100, TW-80, Brij35 & $\mathrm{C} / 5, \mathrm{PS} / 6$ & $85,98.3,95.8$ & {$[29,36,37]$} \\
\hline $\mathrm{Zn}^{2+}$ & SDS & NPE & $\mathrm{C} / 5$ & 99.2 & {$[32]$} \\
\hline $\mathrm{Cr}^{3+}$ & SDS & NPE & $\mathrm{ZrO}_{2} / \mathrm{TiO}_{2}$ & 99.5 & {$[31]$} \\
\hline $\mathrm{Pb}^{2+}$ & SDS & TX-100, NP & PES/10 & 98.4/98.7 & [38] \\
\hline
\end{tabular}

$\mathrm{S}=$ surfactant, $\mathrm{M}=$ membrane type, $\mathrm{R}=$ removal, $\mathrm{C}=$ cellulose, $\mathrm{PS}=$ polysulfone, $\mathrm{PES}=$ ployethersulfone

Generally, medium size of micelles are considered, but change of surfactant concentration even during experimentation results in change of micellar aggregates like spherical or ellipsoid which ultimately change micelles size as studied a change in sodium dodecyl sulfate (SDS) micelle size with increasing SDS concentration [15]. When surfactant concentration increased viscosity of the solution goes higher as stated in a case of Triton X-100 (TX-100) solutions [16]. The different ionic environments can be the reason of micelles size change [17] and further change can be due to incorporated hydrophobic matter. The micelles size also depends on temperature as reported a decrease in SDS micelle size with increasing temperature [15]. It is indicated that surfactant/membrane interaction and the complex micellization behavior should be considered for the evaluation of MEUF as mentioned in previous studies [18-20]. Generally, in many cases by increasing surfactant to solute ratio higher removal efficiency was observed, mostly obtained above value 10 of surfactant to solute ratio [13, 14]. But at higher concentration of surfactant permeate flux drops drastically as a result of an adsorption layer formation on surface of the membrane. There are number of studies for various surfactants investigation with respect to MEUF performance are presented in Table 1.

It is concluded that in surfactant selection large size micelles formation, low CMC, high solubility of the solute, lower adsorption ability on to the membrane surface and biodegradability are considering factors for better MEUF performance. But all at the same time is not possible therefore; a good solute/surfactant interaction is considered as the basic criteria because otherwise solute removal cannot accomplished in MEUF process. Moreover, surfactants with low CMC and easily biodegradable are preferred due to economical point of view especially where post-treatment is required for surfactant removal. The economic feasibility of the process could be managed by reducing CMC of surfactant by adding non-ionic surfactant $[28,29]$ but removal efficiency of metals decreases slightly with increase of non-ionic surfactant concentration. For example chromate removal was decreased from 93.7 to $84.8 \%$ when concentration of non-ionic surfactant Tween 80 (TW-80)was increased from 10 to $25 \mathrm{mM}$ in the feed solution [30]. In another study at high molar ratio of non-ionic surfactant Brij in the solution not only the CMC of anionic surfactant (SDS) decreased but cadmium removal efficiency was also decreased [25]. Other studies presented the similar results such as for $\mathrm{Cr}^{3+}$ removal by using nonylphenol ethoxylate (NPE) [31], and for zinc removal when NPE was used [32]. Few selected studies with addition of nonionic surfactants are presented here in Table 2.

\subsubsection{MEUF single and mixed systems}

The literature for the removal of single metal ion from solution is presented in Table 3 and previous studies about mixed ion solution are shown in Table 4. By using an appropriate surfactant, the size of the "ion" is enlarged and separation of those ions becomes possible by ultrafiltration. Mostly ionic surfactants with opposite charge to the targeted metal ion are in application for better performance of MEUF process.

Furthermore, in literature simultaneous removal of multiple ions via MEUF process has also been investigated. An overview 
Table 3. Single Metal Ion Removal from Aqueous Solution

\begin{tabular}{|c|c|c|c|c|}
\hline Metal ions & Surfactant & $\mathrm{M} /$ pore size (kDa) & R (\%) & References \\
\hline \multirow[t]{3}{*}{ As } & CPC & PES/100 & 98 & [39] \\
\hline & CPC & $\mathrm{PES} / 5$ & 99 & {$[40,41]$} \\
\hline & CPC/CTAB/ODA/BC & $\mathrm{RC} / 3$ & $>96 / 94 />80 / 57$ & {$[34]$} \\
\hline \multirow[t]{2}{*}{$\mathrm{Cd}^{2+}$} & SDS & $\mathrm{PS} / 6$ & 99 & [25] \\
\hline & SDS & $\mathrm{RC} / 10$ & 99 & {$[35]$} \\
\hline \multirow[t]{5}{*}{$\mathrm{Cu}^{2+}$} & SDS & $\mathrm{PAN} / 5$ & 98 & [10] \\
\hline & SDS & $\mathrm{RC} / 5$ & 98 & [42] \\
\hline & СТАВ & $\mathrm{RC} / 6$ & $>99$ & [43] \\
\hline & RO90 & $\mathrm{RC} / 5$ & 98 & [14] \\
\hline & CPC & $\mathrm{RC} / 10$ & 90 & {$[44]$} \\
\hline \multirow[t]{6}{*}{$\mathrm{Cr}$} & CPC & $\mathrm{PAN} / 100$ & $>99$ & {$[11]$} \\
\hline & CPC & $\mathrm{CA} / 5$ & $>99$ & [8] \\
\hline & СТАВ & $\mathrm{CA} / 0.2 \mu \mathrm{m}$ & $>99$ & {$[45]$} \\
\hline & $\mathrm{RL}$ & $\mathrm{PS} / 10$ & $>98$ & {$[46]$} \\
\hline & CPC & $\mathrm{PS} / 10$ & 99 & [47] \\
\hline & СТАВ & $\mathrm{PS} / 10$ & $>99$ & {$[40]$} \\
\hline \multirow[t]{2}{*}{$\mathrm{Pb}^{2+}$} & SDS & PAN/10 & $>95$ & {$[41]$} \\
\hline & SDS & $\mathrm{CA} / 10$ & $>99$ & {$[48]$} \\
\hline \multirow[t]{3}{*}{$\mathrm{Ni}^{2+}$} & SDS & $\mathrm{PS} / 20$ & $>99$ & [49] \\
\hline & RO90 & $\mathrm{RC} / 10$ & $>95$ & [13] \\
\hline & SLES & $\mathrm{PC} / 0.1 \mu \mathrm{m}$ & $>98$ & {$[50]$} \\
\hline \multirow[t]{4}{*}{$\mathrm{Zn}^{2+}$} & SDS & $\mathrm{RC} / 10$ & $>99$ & {$[51]$} \\
\hline & SDS & $\mathrm{PAN} / 300$ & $>80$ & [52] \\
\hline & RO90 & $\mathrm{RC} / 10$ & $>95$ & {$[13]$} \\
\hline & SDS & PS/6 & 99 & [53] \\
\hline
\end{tabular}

$\mathrm{M}=$ membrane type, $\mathrm{R}=$ removal, $\mathrm{BC}=$ Benzalkonium chloride, $\mathrm{RL}=$ Rhamnolipids

Table 4. Simultaneous Removal of Multiple Ions via MEUF

\begin{tabular}{|c|c|c|c|c|}
\hline Ions & S/conc. (mM) & $\mathrm{M} /$ pore size $(\mathrm{kDa})$ & R (\%) & References \\
\hline $\mathrm{Ni}^{2+} / \mathrm{Co}^{2+}$ & SDS/7 & $\mathrm{PS} / 20$ & $>99$ & [55] \\
\hline $\mathrm{Co}^{2+} / \mathrm{Cu}^{2+}$ & SDS/14 & $\mathrm{PES} / 30$ (a) & $85.6 / 29.3$ & {$[56]$} \\
\hline $\mathrm{Ni}^{2+} / \mathrm{Zn}^{2+}$ & SDS/12.75 & $\mathrm{PAN} / 100$ & $96.3 / 96.7$ & [57] \\
\hline $\mathrm{Cd}^{2+} / \mathrm{Cu}^{2+} / \mathrm{Zn}^{2+}$ & SDS/100 & $\mathrm{CA} / 5$ & $>99$ & [58] \\
\hline $\mathrm{Cd}^{2+} / \mathrm{Cu}^{2+} / \mathrm{Co}^{2+} / \mathrm{Zn}^{2+}$ & $\mathrm{SDS} / 30$ & $\mathrm{RC} / 3$ & $>90$ & {$[59]$} \\
\hline $\mathrm{Fe}^{2+} / \mathrm{Cu}^{2+} / \mathrm{Cd}^{2+} / \mathrm{Zn}^{2+} / \mathrm{Ni}^{2+} / \mathrm{Mg}^{2+}$ & $\mathrm{RO} 90 / 2$ & $\mathrm{RC} / 10$ & $>95 />95 / 55-70 / 40(b)$ & [13] \\
\hline
\end{tabular}

$\mathrm{S} /$ conc. = Surfactant concentration, $\mathrm{M}=$ membrane type, $\mathrm{R}=$ removal, (a) $\mathrm{pH}$ is 4.8 and chelating conc. is $3 \mathrm{mM}$, (b) removal efficiency varies for $\mathrm{Cd} / \mathrm{Zn} / \mathrm{Ni}$ between $55-70 \%$ and $\mathrm{Mg}^{2+}$ is least $40 \%$.

is presented in Table 4. In case of single ion removal, ions are attracted by the charged surface of the micelles until the binding capacity is attained. But if multiple ions are present in the solution then they compete for the binding sites at micelles surface, references are provided for detailed studies. A study regarding simultaneous removal of different metals as presented in Table 4 showed that removal efficiencies were varied as $\mathrm{Fe}^{2+} / \mathrm{Cu}^{2+}>\mathrm{Cd}^{2+}>$
$\mathrm{Zn}^{2+}>\mathrm{Ni}^{2+}>\mathrm{Mg}^{2+}$ because of different complex binding constants as studied earlier by Bunting and Thong for different alkyl carboxylates [54].

\subsubsection{Membranes}

An appropriate membrane selection is a basic criterion for the required separation. In membrane selection most significant points 
including, membrane material, surface properties (hydrophilic, hydrophobic or charged surface) and MWCO/pore size. Mostly polymeric membranes are made of polyethersulfone (PES), polysulfone (PS), cellulose acetate (CA), regenerated cellulose (RC), polyacrylonitrile (PAN), polyvinylidene difluoride (PVDF), polytetrafluoroethylene (PTFE) and polyamide (PA). Moreover, previous studies confirmed that ceramic membranes application in MEUF can withstand under high temperature and highly acidic or basic environment [39, 60, 61]. In PA membranes micelle adsorption occur preferentially on the hydrophilic surface rather than hydrophobic surfaces of ceramic or PS membranes [62]. In hydrophilic membranes more than one layer either a second layer is adsorbed on the first layer or adsorbed clusters are formed where hydrophilic head groups are in the outer layer and make the surface more hydrophilic as shown in Fig. 3.

On the other hand, surfactant adsorption phenomena on hydrophobic membrane surface are either formation of a monolayer or semi-spherical clusters. The tail groups are adsorbed on to the hydrophobic membrane surface and are in direct contact to the aqueous medium while adsorption of head groups occurs on to hydrophilic membranes surface Fig. 3 [63]. The MWCO of the membrane corresponds with pore size and has to be selected according to the size of micelles. Larger pore sized membranes are known to cause earlier development of the concentration polarization and reduced the release of the surfactant at the permeate [39]. A comparative study to investigate metal ions removal by using different material and pore size membranes is presented in Table 5 .

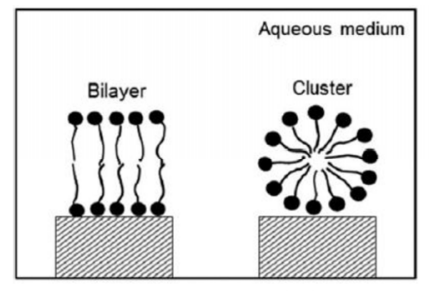

Hydrophilic membrane surface

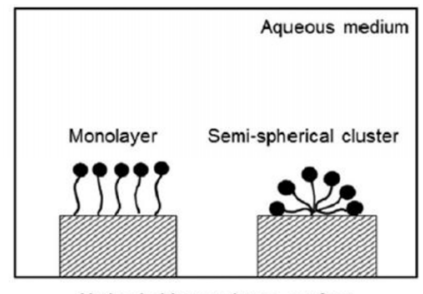

Hydrophobic membrane surface
Fig. 3. Surfactant adsorption on hydrophilic and hydrophobic membrane surfaces [63].

\subsubsection{Operating parameters affecting MEUF process}

Efficiency of the MEUF process depends upon various operating parameters including, operating pressure, type and concentration of surfactant, $\mathrm{pH}$ of the solution, temperature, presence of additives, and the presence of ions and salt. Effects of these parameters on the removal efficiency of heavy metals through MEUF process are summarized below.

\subsubsection{Effect of operating pressure}

In MEUF pressure is the driving force for ultrafiltration which is much lower than nano-filtration for the removal of small sized molecules. Various studies conducted to investigate the influence of pressure on MEUF performance for the removal heavy metals. MEUF application for hexavalent chromium ion removal depicted that flux variation at three different pressure values is negligible due to least effect of concentration polarization. While, CPC retention increased at high pressure due to the compaction of the micellar aggregation layer (MAL) [47]. In the removal of single metal ion it was reported that there is no significant effect of transmembrane pressure on the metal removal [61]. Another study presented that transmembrane pressure (TMP) had significant influence on the flux. It depicted that increase in TMP resulted in higher flux such as $30.20 \mathrm{~L} / \mathrm{m}^{2} \cdot \mathrm{h}$ at $0.05 \mathrm{MPa}$ while increased up to $80.15 \mathrm{~L} / \mathrm{m}^{2} \cdot \mathrm{h}$ at $0.20 \mathrm{MPa}$ but SDS retention by membrane was decreased from $79 \%$ to $53 \%$ at 0.05 and $0.20 \mathrm{MPa}$, respectively [19].

The average chromate removal efficiency was $82 \%, 81 \%$ and $77 \%$ at retentate pressure of $0.2,0.18$ and $0.14 \mathrm{MPa}$, respectively. At higher pressure layers at membrane surface are compacted and causing more retention of a broken micelle [70]. As a result of pressure increase a secondary resistance to the metal ions passing through the membrane was increased quickly [23]. The CPC in permeate increases with the increase of pressure but not higher than CMC and only possible if CPC concentration in the feed solution exceeds the critical feed concentration [47]. A relation between N-lauryl-N,N-dimethylaminoxide (LDAO) a non-ionic surfactant concentration in the feed solution and the total permeate flux was studied at 0.3 and $0.5 \mathrm{MPa}$ pressure [71]. Independent of pressure, total permeation fluxes decreased in the range of 0.012-0.03 by weight $\%$ of surfactant concentration in the feed

Table 5. Metal lons through Membranes of Various Materials and MWCO (see reference for details)

\begin{tabular}{|c|c|c|c|c|c|}
\hline Metal ions & Membrane & Surfactant & MWCO (kDa) & Removal \% & References \\
\hline $\mathrm{Cr}$ & PAN & CPC & 100,300 & 98,97 & {$[64]$} \\
\hline Cr, Nitrate & $\mathrm{RC}$ & CPC & 3,10 & $>99,97$ & [65] \\
\hline Cr, Nitrate & PES & CPC & 8 & $>99,91$ & {$[66]$} \\
\hline $\mathrm{Cd}^{2+}$ & PAN & SDS & 100,300 & $68.5,36.4$ & [67] \\
\hline As & PES & CPC & 5,10 & $100,95.5$ & [68] \\
\hline As & $\mathrm{RC}$ & CPC & 10 & 99 & [68] \\
\hline $\mathrm{Ni}^{2+}, \mathrm{Zn}^{2+}$ & PAN & SDS & 100,300 & $96.3,96.7$ & {$[57]$} \\
\hline $\mathrm{Zn}^{2+}$ & $\mathrm{RC}$ & SDS & 3,10 & $98.49,98.04$ & {$[51]$} \\
\hline $\mathrm{Cu}^{2+}$ & PAN & SDS & 100,300 & $95,<90$ & {$[10]$} \\
\hline $\mathrm{Ni}^{2+}$ & PAN & SDS & 100,300 & $83,72.3$ & [69] \\
\hline $\mathrm{Zn}^{2+}$ & PAN & SDS & $30,100,300$ & $91.47,81.40,79.06$ & [60] \\
\hline
\end{tabular}


solution and farther than this range results were similar to pure water. Above CMC, surfactant passage to permeate decreased when applied pressure was increased because membrane resistance to LDAO was increased due to compaction of membrane. According to this study surfactant pre-micelles exist in dynamic conditions that is in agreement as reported in another paper [72]. It can be concluded that at higher pressure the layers at membrane surface are compacted and causing more retention by providing a secondary resistance to the metal ions and micelles passing through the membrane and resultantly higher removal efficiency especially surfactant retention was achieved.

\subsubsection{Effect of surfactant concentration}

The surfactant concentration of feed solution is very important parameter in MEUF process. A study for single metal removal including $\mathrm{Cs}^{+}, \mathrm{Sr}^{2+}, \mathrm{Mn}^{2+}, \mathrm{Co}^{2+}, \mathrm{Cu}^{2+}, \mathrm{Zn}^{2+}$, and $\mathrm{Cr}^{3+}$ from aqueous solutions by using SDS indicated that a sharp decrease in permeate flux was noted when SDS concentration goes beyond $5 \mathrm{mM}$ although CMC of SDS is $8.3 \mathrm{mM}$. It was assumed theoretically that below CMC, no micelles are present in the solution, however it concluded that may be there is an accumulation of SDS at the membrane surface. The removal efficiency of each metal ion except $\mathrm{Cs}^{+}$increased along with increment of surfactant to metal ratio but above 10 there was no significant effect on metal removal efficiency [61]. The chromate and nitrate removal efficiency through MEUF was increased when surfactant concentration was on higher side as expressed in terms of molar ratio ranges (1:1:10) chromate/nitrate and CPC ratio, respectively. Another study done by the same author for chromate and ferric cyanide removal by using CPC presented the similar results as aforementioned [73, 74]. The chromate removal was found $99.5 \%, 98.6 \%$ and $77.0 \%$ and CPC removal efficiencies were $76.2 \%, 60.7 \%$ and $53.5 \%$, at the molar ratios of $1: 10,1: 5$ and 1:2, respectively [11]. In this study permeate flux was noted as $33.3 \mathrm{~L} / \mathrm{m}^{2} . \mathrm{h}, 30.4 \mathrm{~L} / \mathrm{m}^{2} . \mathrm{h}$ and $24.6 \mathrm{~L} / \mathrm{m}^{2} . \mathrm{h}$ for the molar ratios of chromate to CPC at $1: 2,1$ : 5 and 1:10, respectively. The accumulation of more micelles occur on the membrane surface at higher CPC concentration which reducing the driving force and therefore, decreasing the permeate flux [11]. A previous study about the influence of CPC surfactant molar ratios on the removal of nitrate and phosphate presented the similar results [73].

The permeate flux and chromate rejection was studied as a function of CTAB surfactant concentration in the feed solution at a fixed concentration 2.10-4 $\mathrm{M}$ of chromate feed solution. It was illustrated that chromate rejection was above $80 \%$, even below the CMC of surfactant, where micelles are not present. The higher surfactant concentration causes a gel layer formation on the membrane surface which shows micelles presence and results in concentration polarization [40]. Zinc rejection studies by using low surfactant concentration with anionic nonionic surfactant mixture reported analogous results [32]. The surfactant removal is a significant factor for the effluent to be discharged in to the environment. The removal of CPC surfactant was increased from $80 \%$ to $95 \%$ when the surfactant concentration in the feed solution increased from 5 to $10 \mathrm{mM}$ [34]. Due to the concentration polarization CPC concentration at the membrane surface reached CMC even though the feed solution concentration was less than CMC.
Previous studies showed that it resulted in higher surfactant removal efficiency through MEUF [40, 47, 55, 56, 75]. Arsenic (V) removal was $98 \%$ at $1-3 \mathrm{mM}$ CPC concentration by using large MWCO membrane [39]. Several studies for heavy metals removal by using anionic surfactants such as SDS and sodium dodecyl benzonate sulfonate (SDBS) showed that at CMC molar ratio of SDS to copper of 5:1 was efficient for the removal of copper [76]. Moreover, 93\% copper removal efficiency was reported at 8.5 mM SDS concentration. The removal of $\mathrm{Zn}^{2+}$ increases with increasing the surfactant to metal ratio as expressed at or above 24.4 ratio of SDS to $\mathrm{Zn}^{2+}$ the retention of $\mathrm{Zn}^{2+}$ rises up to $91 \%$ [77]. The retention of $\mathrm{Cr}^{3+}$ below CMC of SDS was 33\% increased up to $99 \%$ at the CMC [31]. A comparative study of anionic surfactants such as SDBS and SDS indicated that SDBS was more efficient for the removal of heavy metals as well as for the organics [74, 78].

The micelles size plays an important character in the removal of a targeted ion in MEUF process. As expressed in literature that micelle normal size is $5.07 \mathrm{~nm}$ at CMC of SDS, while beyond CMC micelle size decreased and its shape was changed. As concern to ultrafiltration membrane linear molecule passes through but globular molecules with similar molecular weight may be retained [79]. It was observed that solubilization capacity of the CPC micelle decreased on farther addition of CPC above $30 \mathrm{mM}$ [80]. CMC of surfactant depends upon various parameters such as temperature, $\mathrm{pH}$, presence of non-ionic surfactant and inorganic salt. It was noted that CMC of ionic surfactants is much higher than nonionic surfactants even though containing equivalent hydrophobic groups in an aqueous medium [81]. CMC of some selected surfactants is presented in Table 7. Flux decline is caused by several factors such as concentration polarization, fouling, adsorption of surfactant, gel layer formation, and pore plugging. Therefore, not only the separation efficiency of metal ions and the optimization of process variables but also the flux behaviors in surfactant-based ultrafiltration should be investigated systematically. The study of the permeate flux variation according to the surfactant concentration in the feed revealed that the permeate flux decreases from $73 \mathrm{~L} / \mathrm{m}^{2} . h$ to $32 \mathrm{~L} / \mathrm{m}^{2}$.h, when the concentration in CTAB grows from $10^{-6} \mathrm{M}$ to $10^{-4} \mathrm{M}$. Beyond this concentration, the flux increases, then stabilizes towards a value of 50 $\mathrm{L} / \mathrm{m}^{2}$.h, when the concentration in surfactant varies between $9.10^{-4}$ $\mathrm{CMC}$ and $4.10^{-3} \mathrm{M}[40]$. The surfactant concentration in permeate is always lower than CMC of surfactant regardless of concentration in the feed solution. It is evident from previous studies that higher concentration of surfactant resulted in higher micelles formation and ultimately enhanced the metal ions removal but it produced more severe secondary pollution problem for further treatment.

\subsubsection{Effect of $\mathrm{pH}$}

Literature review showed that $\mathrm{pH}$ of solution has a significant influence for heavy metals removal through MEUF process. The removal efficiency of cationic metals was increased at higher $\mathrm{pH}$ values by the ultrafiltration membrane when SDS was used as surfactant [61]. Due to the competition between $\mathrm{H}^{+}$and cationic metal ions at lower $\mathrm{pH}$ resulted in decreased removal efficiency. Another study presented that there is no effect of $\mathrm{pH}$ in the case of $\mathrm{Sr}^{2+}$ and $\mathrm{Cr}^{3+}$ removal but retention of $\mathrm{Cd}^{2+}$ increased from 83 to $99 \%$ when the $\mathrm{pH}$ of feed solution was changed from 3 
to 11 at a fixed cadmium and SDS concentration $100 \mathrm{mg} / \mathrm{L}$ and $8 \mathrm{mM}$, respectively [25]. The arsenic removal was also influenced by $\mathrm{pH}$, at low $\mathrm{pH}$ the removal of arsenic was low regardless of the membrane MWCO and its type. $\mathrm{As}(\mathrm{V})$ is neutral at $\mathrm{pH} 1.0$, changes from neutral form to mono-anionic form between $\mathrm{pH}$ 2.22-6.98 and at 6.98 mono-anionic form dissociate in to di-anionic form of $\mathrm{As}(\mathrm{V})$. The binding of di-anionic arsenate is greater to the micelles of surfactant due to which higher removal of arsenic was found at $\mathrm{pH}$ 8. In this study arsenic concentration in permeate was noted as $20 \mathrm{ppb}$ and $0 \mathrm{ppb}$ at $\mathrm{pH}$ of 5.5 and 8 , respectively, with an initial arsenic concentration of $221 \mathrm{ppb}$ when $10 \mathrm{kDa}$, PES membrane was used for filtration. But decline of flux was observed as the removal was increased which caused concentration polarization [68]. Another study for arsenic removal presented similar results of the influence of $\mathrm{pH}$ by using cationic surfactants: CPC, CTAB and octadecylamine acetate [34]. The removal efficiency was not decreased significantly even at lower $\mathrm{pH}$ because of high surfactant concentration. Copper removal through MEUF and activated carbon fiber hybrid process was sharply dropped at a lower $\mathrm{pH}$ [10] and other previous work has also reported similar results of $\mathrm{pH}$ effect on the removal efficiency of zinc, cadmium and cobalt [82, 83]. The effect of $\mathrm{pH}$ in MEUF process is dependent on the nature of solute and surfactant. In case of cations removal, $\mathrm{pH}$ is maintained as per required but after filtration, for the easy separation of solute and surfactant $\mathrm{pH}$ was lowered [14]. In addition, the interaction between solute and micelles also depends upon the $\mathrm{pH}$ value. At lower $\mathrm{pH}$, the adsorption of cations is hindered due to the protons coordination to the micelles when pure anionic surfactants are used, while at higher $\mathrm{pH}$ values, more "free" groups are available to trap cations [10].

\subsubsection{Effect of temperature}

Literature review showed that temperature influences the solubility, CMC of the surfactant, viscosity of solution and micelle properties like size of the micelles. The CMC of surfactants is a function of temperature. A study providing the influence of temperature on SDS anionic surface active agent removal from a water solution through ultrafiltration by calculating their CMC values that amounted as $2,257 \mathrm{~g} / \mathrm{m}^{3}, 2,445 \mathrm{~g} / \mathrm{m}^{3}$, and $2,706 \mathrm{~g} / \mathrm{m}^{3}$ for 25,40 , and $55^{\circ} \mathrm{C}$, respectively [84]. This increase in CMC indicates that the demicellization occurs at high temperature due to the breakage of palisade layer of the micelle, resultantly, detachment of surfactant ions from micellar bulks happened [84]. The permeate flux also increased at high temperature due to the decreases in solution viscosity and thermal expansion of the membrane and this increment of flux causes higher concentration polarization [84]. The krafft point is the temperature at which the solubility of an ionic surfactant becomes equal to the CMC [74] and below this krafft point, precipitation of the ionic surfactant occurred. The cloud point is a temperature above which an aqueous solution of nonionic surfactant will separate into surfactant-rich and water-rich phases. The cloud-point temperature for nonionic surfactants depends upon hydrophilic character of the surfactant as previous studies showed that nonionic surfactants have cloud-point temperature below $100^{\circ} \mathrm{C}$, e.g. TX-100 $\left(65^{\circ} \mathrm{C}\right)$ or $\mathrm{TX}-114\left(24^{\circ} \mathrm{C}\right)[85]$ and this temperature value can change accord- ing to the presence of solutes. In case of ionic surfactants cloud-point temperature is higher than $100^{\circ} \mathrm{C}$ because of the solubility of ionic surfactants increases as temperature rises. Additionally, the viscosity of solution depends upon the temperature and has a significant influence on the filtration process because temperature increase results in viscosity decrease which ultimately increases flux through membrane [7]. The resistance offered by surfactant during filtration was studied which indicated that hexa-decyl tri-methyl ammonium bromide and alkyl poly-glucoside solutions caused a small additional resistance but SDS solution added a strong resistance to the membrane at high temperature. The reason behind the minimum resistance of CTAB solutions is the high krafft point 250C, while krafft point of SDS is $210 \mathrm{C}$ [23]. Therefore, it is assumed that gel formation take place and penetrate in to the membrane pores due to stress applied and then transfer to the inactive side of the membrane. The concentration of phenol and surfactant CPC in permeate increases with temperature. The properties of CPC changes like critical micellar concentration, degree of counter-ion dissociation increase and micelles aggregation decrease with temperature increase [86]. Hence, more CPC monomer and phenol molecules pass through the ultrafiltration membrane to product stream. As mentioned earlier permeate flux increases with temperature due to the decrease in viscosity of solution and membrane pore size expansion occurred that ultimately resulted in lower retention of metal and surfactant ions.

\subsubsection{Effect of dissolved ions}

\subsubsection{Effect of salt concentration}

In previous studies effect of salt addition in feed solution for MEUF separation process, was investigated. The addition of $\mathrm{NaCl}$ minimized the surfactant leakage to permeate stream because it drops the CMC of the surfactant which leads to an efficient removal of surfactant micelle through ultrafiltration membranes [75]. The addition of $\mathrm{NaCl}$ can decrease the CMC of ionic surfactants because it can weaken the repulsive forces between the head groups, which are usually fighting against the aggregation of surfactant monomers. Thus, in the presence of an electrolyte micelles formation is comparatively easy. Another study presented that $\mathrm{Cd}^{2+}$ removal efficiency in the presence of $\mathrm{NaCl}$ using SDS

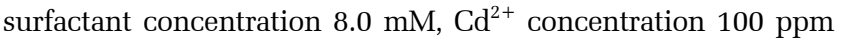
at the transmembrane pressure $0.07 \mathrm{MPa}$, decreased with the increase of the $\mathrm{NaCl}$ concentration from 10 to $100 \mathrm{mM}$ [25]. This may be attributed to the cation $\mathrm{Na}^{+}$which can occupy the available binding sites. Resultantly, the $\mathrm{Cd}^{2+}$ removal efficiency decreases with the increase of the $\mathrm{NaCl}$ concentration. In addition anions $\mathrm{Cl}^{-}$presence, can form the complexes with $\mathrm{Cd}^{2+}$ metal ions [31].

The enhanced polarization concentration on the membrane surface caused by increasing electrolyte concentration resulted in drop of permeate flux when $\mathrm{C}_{16} \mathrm{TAB}$ is used as surfactant. The permeate flux drop in the presence of $\mathrm{Na}_{2} \mathrm{SO}_{4}$ was higher than $\mathrm{NaCl}$ [87]. The presence of an electrolyte causes a decrease in the CMC of cationic surfactant, the effect being more significant for bivalent as compare to monovalent anion [88]. On addition of salt in a solution water is attracted to salt ions and organics are aided to attach with the micelles due to salting out effect as demonstrated for phenols [78]. It was observed that the repulsive 
forces of SDS head group monomer decreased in the presence of salt, due to the electrostatic shielding effect results in the formation of a micelle below CMC [25]. The electrostatic attraction between ions and the micelles decreased because of high concentration of electrolyte that actually, compresses the electrical double layer. In case of $\mathrm{As}(\mathrm{V})$ and $\mathrm{CPC}$ surfactant system, metal closely binds with surfactant which causes decrease in electrical charge and ultimately drop the CMC [68]. The CMC of SDS (0.8)-NPE (0.2) decrease on addition of $\mathrm{NaCl}$ which is beneficial in terms surfactant consumption in MEUF process. Furthermore, addition of $0.05 \mathrm{M}$ concentration of $\mathrm{NaCl}$ at dosing rate of $0.05 \mathrm{~mol} / \mathrm{dm}^{3}$ results in decrease of removal from 99.65 to $92.21 \%$. The $\mathrm{Cr}^{3+}$ removal efficiency drops to $53.50 \%$ by adding $0.9 \mathrm{mM} \mathrm{NaCl}$ at the rate of $0.9 \mathrm{mmol} / \mathrm{dm}^{3}$ [31]. It may be caused due to the adsorption of sodium cations at the micelle surface competing $\mathrm{Cr}^{3+}$

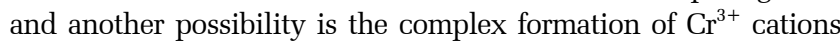
with chloride. On the contrary, addition of 1 to $500 \mathrm{mM}$ of $\mathrm{NaCl}$ revealed that CPC concentration in the permeate stream decreases from 1 to $0.15 \mathrm{mM}$ as well as chromate removal remains above $90 \%$, even at the concentration of $100 \mathrm{mM}$ of $\mathrm{NaCl}$ but removal decline to $46 \%$ at $0.5 \mathrm{M}$ of $\mathrm{NaCl}$ [40]. A study to investigate the effects of $\mathrm{NaCl}$ addition on the removal of two surfactants including CTAB and linear alkyl benzene sulfonate (LABS), indicated that $\mathrm{CTAB}$ removal rate was increased from $68 \%$ to $98 \%$ in the presence of $2 \mathrm{mM}$ and $100 \mathrm{mM}$ of $\mathrm{NaCl}$, respectively. On the other hand, LABS removal rate decreased somewhat from $38 \%$ to $34 \%$ at the same concentrations of $\mathrm{NaCl}$ as mentioned before. Generally, permeate flux decreases by adding electrolyte but metal removal efficiency depends upon the nature of solute. Moreover, the salt ions presence results in a competition with the solute or the surfactant that finally drop the removal efficiency of both metal and surfactant. Despite of disadvantage of the presence of salts in the solution this competition of ions is helpful in separation of surfactant after MEUF process.

\subsubsection{Effect of additives}

The metal and surfactant removal decrease in the presence of ligands like presence of di-amino ethane tetra-acetic (EDTA), drops copper removal from 95 to $40 \%$ as well as SDS concentration in the permeate stream was above CMC [44]. The decrease in copper removal can be elucidated by the competitive complexation of copper with SDS and ligands. In this study three ligands were used and noted different copper removal efficiency for each ligand based on copper-ligand affinity. It was mentioned that $10^{9.55}, 10^{7.82}$, and $10^{7.57}$ are complexation constants of copper with EDTA, nitrile tri-acetate (NTA), and citric acids, respectively and EDTA, competition was strong due to the highest complexation constant which results in lowest copper removal. The addition of CPC favors the complexation between CPC and the Cu-ligands and at molar ratio 1:70 of copper to CPC presented removal of copper above $90 \%$.

\subsubsection{Effect of competing metals}

Previous studies presented that the presence of other inorganic pollutants inhibit the metal removal from aqueous solution through MEUF process. It was noted that nitrate removal from the nitrate/chromate/CPC system was below $40 \%$ at the molar ratios of 1:1:1, 1:1:2, and 1:1:3 (nitrate:chromate:CPC). In addition by increasing molar ratio to 1:1:5 and 1:1:10 nitrate removal efficiency was increased from $65 \%$ to $80 \%$. The nitrate removal efficiency was suppressed significantly in the presence of chromate as compare to single component nitrate/CPC system. On the other hand, chromate removal was increased as compare to chromate/CPC system. In the mixed system, removal efficiency of chromate increases from $50 \%, 71 \%, 90 \%$, and $98 \%$ at the molar ratios of $1: 1: 1$ to $1: 1: 2$, to $1: 1: 3$, and to 1:1:5 (nitrate:chromate:CPC), respectively [65]. The decrease in nitrate removal was because of different binding powers of anions and cationic surfactant micelles. Another study reported that differences in the rejection of nitrate, sulfate, and chromate resulted from the differences in valences of ions in the polyelectrolyte-enhanced ultrafiltration [88]. The ferric cyanide removal from a mixed system of chromate/ferric cyanide/CPC system reported that removal of ferric cyanide increased over 99\% at molar ratio above 4, which indicates that presence of chromate has no effect on ferric cyanide binding with CPC micelle because ferric cyanide have due to higher affinity. While, chromate removal by using 3,000 MWCO membrane decreased to $18 \%, 24 \%$, and $38 \%$ and $8 \%, 18 \%$, and $23 \%$ for 10,000 MWCO membrane at $1: 1: 1,1: 1: 2$, and $1: 1: 4$ molar ratios, respectively. At higher molar ratios 1:1:6 and 1:1:10, chromate removal was increased to $74 \%$ and $98 \%$ with MWCO of 3,000 and $64 \%$ and $98 \%$ in MWCO of 10,000. It is evident that molar ratio below 1:1:4 ferric cyanide compete chromate ions for binding to CPC micelles, as a result, ferric cyanide bound to CPC micelles preferentially, and after saturation chromate to CPC micelles binding occurs which can be proved by increasing molar ratio [82]. The presence of competing ions in the solution resulted in decrease of removal efficiency of a specific ion and caused an increase of the other ion because of different binding powers of anions and cationic surfactant micelles.

\section{Modification and Combination of MEUF Process}

The application of surfactant in MEUF cause secondary pollution in the water stream, therefore, surfactant concentration is a concern and should be dealt with [66, 82, 89]. To combat this issue different combinations of MEUF are used and this section will present those modified MEUF techniques.

\subsection{MEUF and Electrolysis Combination}

A hybrid process combining MEUF and electrolysis process to retain metals where electrolytic process removes metal ions continuously from the system and detaching them from surfactant micelle-metal complexes. Afterwards, surfactant micelles are capable to retain metal ions entering the system. A comparative study for copper removal by using membrane only, membrane-electrolysis and MEUF processes, showed that copper removal efficiency through integrated hybrid system was better with less surfactant consumption and shorter hydraulic retention time than others [83]. Although copper removal efficiency of the hybrid system is better through electrolysis-membrane process, but addition of SDS further increased the ability of retaining and concentrating copper for higher copper removal. 


\subsection{Combination with Polyelectrolyte-enhanced Ultrafiltration}

In polyelectrolyte-enhanced ultrafiltration (PEUF), surfactant is replaced with polyelectrolytes which results in change of type of formed micelles. The removal efficiency of lead and calcium by using polyacrylic acid (PAA) as a polyelectrolyte at $\mathrm{pH} 4$, was noted as $97 \%$ and $25 \%$, for $\mathrm{Pb}$ and $\mathrm{Ca}$, respectively [90]. Previous studies proved that ultrafiltration is an acceptable technique for the removal of solutes by using surfactant micelles and polyelectrolytes.

\subsection{MEUF Combination with Flocculation}

The MEUF combination with flocculation is efficient as presented, by addition of $\mathrm{Al}^{3+}$ in the solution of $\mathrm{Zn}^{2+}$ and SDS micelle, flocculants supported the micelles floc formation and increased zinc removal efficiency [91]. But a competition between $\mathrm{Zn}^{2+}$ and $\mathrm{Al}^{3+}$ arise to catch the micelles surface at higher concentration of zinc which results in decrease of flocculation. Another study illustrated that resistance to gelation is more for combined $\mathrm{Al}^{3+}$ and SDS as compare to free SDS micelles [92]. Moreover, fouling chances are higher in the presence of colloidal matter and due to partial flocculation and micelles flocculation stopped the micelles to form larger ones.

\subsection{MEUF Combination with Ligands}

In this process ligands are used in addition to surfactants for complex formation which solubilize in the micelles for maximum removal of the targeted ions. In a study copper removal efficiency was investigated by using three different ligand including EDTA, NTA, and citric acid. The copper removal efficiency decreased with increasing ligand/copper ratio due to the competition between ligand and SDS in copper complex formation [44]. It was observed that by increasing the concentration of water soluble polymeric ligands, the complexation-ultrafiltration becomes more productive because of concentration polarization on the membrane surface and thus metal removal increases [93]. On the contrary, cationic surfactants application presented higher removal efficiency such as CPC as a surfactant and NTA as ligand showed copper removal $>90 \%$, but decreased with increasing EDTA ligand concentration. The results of CPC as surfactant comply with results when CTAB is used as surfactant as studied by [43]. Moreover, removal of Pd and Pt by using PADA as ligand, was noted as $98 \%$ and $2 \%$, respectively when SDS used as a surfactant which was caused due to a much stronger complex of ligand with Pd [94]. Few examples are summarized in Table S2, for further experimental parameter values check the references.

\subsection{MEUF Combination with Active Carbon Fiber (ACF)}

Another combination of MEUF-ACF process, where after MEUF, ACF is used to remove the residual surfactant through adsorption $[10,11,41,57]$. This technique is helpful to remove metal ions as well as surfactant efficiently through adsorption. Previous studies with application of MEUF-ACF are presented in Table S3. In conclusion, ACF combination with MEUF proved a good quality control system for metal removal from an aqueous solution. According to previous studies MEUF is an efficient and applicable technique for heavy metals removal from aqueous solution but secondary pollution caused by surfactant should be addressed before being discharged or recycled for industrial applications. For economic point of view combination of MEUF-ACF process is more complex, costly and surfactant recovery is also a challenge. For better performance of MEUF process, the researchers should focus on selecting best possible combination of membranes and surfactants.

\subsection{MEUF Combination with Ozone $\left(\mathrm{O}_{3}\right)$ and Powdered Activated Carbon (PAC)}

In a study efficient removal of SDBS surfactant was reported by using $\mathrm{O}_{3}$ and PAC where oxidation of $\mathrm{OH}$ radicals and adsorption of organic occur on to the PAC surface [95]. In this technique $18 \%$ of SDBS removed by $\mathrm{O}_{3}$ at the concentration $2.8^{*} 10^{-5} \mathrm{M}$ of SDBS while overall removal was more than $70 \%$ within 5 min. of hydraulic retention time [95]. Another chromate removal study by CTAB-enhanced cross flow microfiltration (CFMF) process was found $18-78 \%$, it could be increased up to $88-90 \%$ approximately by addition of PAC to the CTAB-enhanced CFMF process. Furthermore, CTAB removal by using CTAB-enhanced CFMF was almost in the range of $10-54 \%$, while addition of PAC enhanced CTAB removal up to 78.5-92.5. It is evident from this study that addition of PAC to surfactant-enhanced MF resulted in the increase of both chromate and CTAB removal about 90\% [96]. But at higher dosing rate of PAC both chromate and CTAB removal decreased. In this study authors also stated that PAC size should be large enough to avoid the clogging of micro-filter.

\section{Future Recommendations for MEUF Process}

\section{Optimization}

As mentioned earlier in this review paper MEUF is an adaptable separation technique for the removal of various pollutants from aqueous solutions, but till now it has not been accepted in water treatment. Although application of MEUF to real wastewater presented good results including $>98 \%$ arsenic removal by using CPC as surfactant [33], cadmium $84 \%$, copper $75 \%$ when SDS was used as surfactant [97] and > 95\% removal of lead by using SDS/TX-100 [38] surfactant but currently there is no industrial scale application yet.

MEUF has disadvantages which should be addressed first before scaling up and for further industrial applications. The one of the important problem is the secondary pollution caused by surfactants and it requires post treatment of permeate water [7, 9, 98]. It was noted in various studies that surfactants have high CMC values and are less biodegradable so it is need of hour to search for such surfactant which have low CMC to forms large micelles with very good binding properties and must be biodegradable. Despite the fact that bio-surfactant are environmentally friendly but available studies with application of bio-surfactants in MEUF process are limited which should be extended further for future research work. Additionally, the suitable and economical techniques for surfactant recovery are equally important because without surfactant recovery MEUF process is not economical as it requires fresh surfactant for every batch to remove targeted pollutant. 
Another major problem in MEUF process is the flux, which can be controlled by the operating conditions. Due to large flow rates of real wastewater treatment plants high flux of MEUF process is needed. To handle large volume in short time is possible by increasing either membrane surface area or the permeate flux. It is hard and uneconomical to increase membrane surface area so only by increasing permeate flux we can minimize this problem. In operating conditions pressure is the only one parameters which can increase the flux up to a certain value in previous studies we observed that flux can be increased by an external electric field application but this might be difficult on a larger scale. Moreover, membrane fouling decreases the life of membrane and ultimately increases operational cost, therefore fouling-resistant membranes which have minimum surfactant adsorption capacity are required. In the last, most of previous studies were done with simulated water and future studies with real water will present a better idea of MEUF performance in the presence of other ions and salts. As per studies, water treatment via MEUF is uneconomical and environmental issues are also there due to which this technique is not operable on large scale applications. But the basic concept of MEUF, opened new horizons for recovery and separation of valuable metals like catalysis recycling in various industries other than water treatment.

\section{Conclusions}

As shown by the multiple examples in this review, for either removal or recovery of solutes, MEUF is a versatile technique which allows for an efficient treatment of aqueous solutions containing solutes at lower concentrations. The selection of appropriate process conditions is the key to a successful application of MEUF. A variety of heavy metals can be applied for which a desired interaction with the surfactant can be established, finally resulting in enrichment factors $>99 \%$. These high values are not limited to aqueous solutions of single solutes only and can be extended to mixtures of different solutes, e.g., multiple ions. The interaction of the solute/s with the micelles is an important parameter to obtain a higher efficiency in MEUF process with respect to removal/recovery and can be evaluated based on different ways, e.g. by solute distribution, loading of micelles, or even solute adsorption on the micelles. A higher surfactant concentration will result in a higher number of micelles, but lower loading of the micelles. Many examples showed that a molar surfactant-to solute ratio of 10 is sufficient to obtain high retention values in MEUF. However, the flux is determined by the interaction of the surfactant/micelles with the membrane under applied process conditions. Usually, flux decreases with increasing of surfactant concentration, but as shown in this paper, the application of an external electric field might be beneficial for flux enhancement in the presence of ionic surfactants. Otherwise, an optimal surfactant concentration with respect to flux and removal/recovery efficiency must be found. Although many of the reviewed papers perform single-step MEUF, a multi-step MEUF process with different membranes (for high flux or high retention) could result in better performance, but there can be a question of operational costs. One of the major problems of MEUF is still the leakage of surfactant, at least with the surfactant's CMC, into the purified water stream. Some possible methods for lower surfactant discharge were discussed and observed that combined MEUF-ACF process presented better results. As the discharge of surfactant, even at lower concentrations than the $\mathrm{CMC}$, might be problematic for the environment, the application of bio-surfactants or large amphiphilic aggregates with good bio-degradability should be promoted in MEUF. Some research has been already conducted with the application of rhamnolipids. MEUF process has been used for the removal of heavy metals including copper, chromate, zinc, nickel, cadmium, cobalt, serenium, and arsenate. Operating pressure, surfactant concentration, $\mathrm{pH}$ of solution, temperature, presence of nonionic surfactant and salt, membrane type and its pore size and inhibiting additives such as EDTA, citric acid, competing metals highly effect on the removal of heavy metals and surfactants from aqueous solution through ultrafiltration.

\section{Acknowledgments}

This study was conducted by the support from Kumoh National Institute of Technology, Korea (2015-104-162).

\section{References}

1. Fu F, Wang Q. Removal of heavy metal ions from wastewaters: A review. J. Environ. Manage. 2011;92:407-418.

2. Al-Zboon K, Al-Harahsheh MS, Hani FB. Fly ash-based geopolymer for $\mathrm{Pb}$ removal from aqueous solution. J. Hazard. Mater. 2011;1883:414-421.

3. Al-Zboon KK, Al-smadi BM, Al-Khawaldh S. Natural volcanic tuff-based geopolymer for Zn removal: Adsorption isotherm, kinetic, and thermodynamic study. Water Air Soil Pollut. 2016;227:248

4. Hawari AH, Mulligan CN. Biosorption of lead(II), cadmium(II), copper(II) and nickel(II) by anaerobic granular biomass. Bioresour. Technol. 2006;97:692-700.

5. Tenório JAS, Espinosa DCR. Treatment of chromium plating process effluents with ion exchange resins. Waste Manage. 2001;21:637-642.

6. Mohsen-Nia M, Montazeri P, Modarress H. Removal of $\mathrm{Cu}^{2+}$ and $\mathrm{Ni}^{2+}$ from wastewater with a chelating agent and reverse osmosis processes. Desalination 2007;217:276-281.

7. Schwarze M. Micellar-enhanced ultrafiltration (MEUF) - State of the art. Environ. Sci. Water Res. Technol. 2017;3:598-624.

8. Tucker EE. Micellar-enhanced ultrafiltration of chromate anion from aqueous streams. AIChE 1988;34:189-193.

9. Mungray AA, Kulkarni SV, Mungray AK. Removal of heavy metals from wastewater using micellar enhanced ultrafiltration technique: A review. Cent. Eur. J. Chem. 2012;10:27-46.

10. Bade R, Lee SH. Micellar enhanced ultrafiltration and activated carbon fibre hybrid processes for copper removal from wastewater. Korean J. Chem. Eng. 2007;24:239-245.

11. Bade R, Lee SH, Jo S, Lee H, Lee S. Micellar enhanced ultrafiltration (MEUF) and activated carbon fibre (ACF) hybrid processes for chromate removal from wastewater. Desalination 
2008;229:264-278.

12. Anthati VAK, Marathe KV. Selective separation of copper(II) and cobalt(II) from wastewater by using continuous cross-flow micellar-enhanced ultrafiltration and surfactant recovery from metal micellar solutions. Can. J. Chem. Eng. 2011;89:292-298.

13. Schwarze M, Groß M, Moritz M, et al. Micellar enhanced ultrafiltration (MEUF) of metal cations with oleylethoxycarboxylate. J. Membr. Sci. 2015;478:140-147.

14. Schwarze M, Chiappisi L, Prévost S, Gradzielski M. Oleylethoxycarboxylate - An efficient surfactant for copper extraction and surfactant recycling via micellar enhanced ultrafiltration. J. Colloid Interface Sci. 2014:421:184-190.

15. Missel PJ, Mazer NA, Benedek GB, Young CY, Carey MC. Thermodynamic analysis of the growth of sodium dodecyl sulfate micelles. J. Phys. Chem. 1980;84:1044-1057.

16. Mandal AB, Ray S, Biswas AM, Moulik SP. Physicochemical studies on the characterization of Triton X 100 micelles in an aqueous environment and in the presence of additives. J. Phys. Chem. 1980;84:856-859.

17. Moroi Y, Matuura R, Tanaka M, et al. Anionic surfactants with divalent counterions of separate electric charge. 2. Micellar size and surface activity. J. Phys. Chem. 1990;94:842-845.

18. Lipshutz BH, Petersen TB, Abela AR. Room-temperature Suzuki-Miyaura couplings in water facilitated by nonionic amphiphiles. Org. Lett. 2008;10:1333-1336.

19. Huang J, Liu L, Zeng G, et al. Influence of feed concentration and transmembrane pressure on membrane fouling and effect of hydraulic flushing on the performance of ultrafiltration. Desalination 2014;335:1-8.

20. Escadrille A, Niemen N. Ultrafiltration of cetyltrimethylammonium bromide solutions. J. Membr. Sci. 1997;133:1-13.

21. Jönsson A, Jönsson B, Byhlin H. A concentration polarization model for the ultrafiltration of nonionic surfactants. J. Colloid Interface Sci. 2006;304:191-199.

22. Yang JS, Baek K, Yang JW. Crossflow ultrafiltration of surfactant solutions. Desalination 2005;184:385-394.

23. Urbański R, Góralska E, Bart HJ, Szymanowski J. Ultrafiltration of surfactant solutions. J. Colloid Interface Sci. 2002;253:419-426.

24. Colloid JOF, No A. Ultrafiltration of micellar solutions in the presence of electrolytes. J. Colloid Interface Sci. 1996;183: 484-490.

25. Xu K, Zeng G-m, Huang J-h, et al. Removal of $\mathrm{Cd}^{2+}$ from synthetic wastewater using micellar-enhanced ultrafiltration with hollow fiber membrane. Colloids Surf. A Physicochem. Eng. Asp. 2007;294:140-146.

26. Yurlova L, Kryvoruchko A, Kornilovich B. Removal of Ni(II) ions from wastewater by micellar-enhanced ultrafiltration. Desalination 2002;144:255-260.

27. Schwarze M, Rost A, Weigel T, Schom R. Selection of systems for catalyst recovery by micellar enhanced ultrafiltration. Chem. Eng. Process. Process Intensification 2009;48:356-363.

28. Tanhaei B, Chenar MP, Saghatoleslami N, et al. Removal of nickel ions from aqueous solution by micellar-enhanced ultrafiltration, using mixed anionic-non-ionic surfactants. Sep. Purif. Technol. 2014;138:169-176.

29. Tung C, Yang Y, Chang C, Maa J. Removal of copper ions and dissolved phenol from water using micellar-enhanced ultrafiltration with mixed surfactants. Waste Manage. 2002;22:695-701.

30. Lee J, Yang JS, Kim HJ, Baek K, Yang JW. Simultaneous removal of organic and inorganic contaminants by micellar enhanced ultrafiltration with mixed surfactant. Desalination 2005;184:395-407.

31. Aoudia M, Allal N, Djennet A, Toumi L. Dynamic micellar enhanced ultrafiltration: Use of anionic (SDS)-nonionic (NPE) system to remove $\mathrm{Cr}^{3+}$ at low surfactant concentration. $J$. Membr. Sci. 2003;217:181-192.

32. Fillipi BR, Brant LW, Scamehorn JF, Christian SD. Use of micellar-enhanced ultrafiltration at low surfactant concentrations and with anionic-nonionic surfactant mixtures. J. Colloid Interface Sci. 1999;213:68-80.

33. Ergican E, Gecol H, Fuchs A. The effect of co-occurring inorganic solutes on the removal of $\operatorname{arsenic}(\mathrm{V})$ from water using cationic surfactant micelles and an ultrafiltration membrane. Desalination 2005;181:9-26.

34. Iqbal J, Kim HJ, Yang JS, Baek K, Yang JW. Removal of arsenic from groundwater by micellar-enhanced ultrafiltration (MEUF). Chemosphere 2007;66:970-976.

35. Landaburu-aguirre J, Pongrácz E, Perämäki P, Keiski RL. Micellar-enhanced ultrafiltration for the removal of cadmium and zinc: Use of response surface methodology to improve understanding of process performance and optimisation. $J$. Hazard. Mater. 2010;180:524-534.

36. Li C, Liu C, Yen W. Micellar-enhanced ultrafiltration (MEUF) with mixed surfactants for removing $\mathrm{Cu}(\mathrm{II})$ ions. Chemosphere 2006;63:353-358

37. Zhao B, Li R, Zhong J, Zhang L. Micellar-enhanced ultrafiltration of copper ions using sodium dodecyl sulfate and its mixture with Brij 35, Tween 80 and Triton X-100. Water Sci. Technol. 2013;67:2154-2159.

38. Yenphan P, Chanachai A, Jiraratananon R. Experimental study on micellar-enhanced ultra fi ltration (MEUF) of aqueous solution and wastewater containing lead ion with mixed surfactants. Desalination 2010;253:30-37.

39. Beolchini F, Pagnanelli F, De Michelis I, Vegliò F. Treatment of concentrated arsenic(V) solutions by micellar enhanced ultrafiltration with high molecular weight cut-off membrane. J. Hazard. Mater. 2007;148:116-121.

40. Gzara L, Dhahbi M. Removal of chromate anions by micellar-enhanced ultrafiltration using cationic surfactants. Desalination 2001;137:241-250.

41. Son G, Lee S. Application of micellar enhanced ultrafiltration and activated carbon fiber hybrid processes for lead removal from an aqueous solution. Korean J. Chem. Eng. 2011;28: 793-794.

42. Xiarchos I, Jaworska A. Response surface methodology for the modelling of copper removal from aqueous solutions using micellar-enhanced ultrafiltration. J. Membr. Sci. 2008;321: 222-231.

43. Fillipi BR, Scamehorn JF, Taylor RW, Christian SD. Selective removal of copper from an aqueous solution using ligand-modified micellar-enhanced ultrafiltration using an alkyl- $\beta$ -diketone ligand. Sep. Sci. Technol. 1997;32:2401-2424.

44. Liu CK, Li CW, Lin CY. Micellar-enhanced ultrafiltration proc- 
ess (MEUF) for removing copper from synthetic wastewater containing ligands. Chemosphere 2004;57:629-634.

45. Dani Ü, Keskinler B. Chromate removal from wastewater using micellar enhanced crossflow filtration: Effect of transmembrane pressure and crossflow velocity. Desalination 2009;249:1356-1364.

46. Abbasi-Garravand E, Mulligan CN. Using micellar enhanced ultrafiltration and reduction techniques for removal of $\mathrm{Cr}(\mathrm{VI})$ and Cr(III) from water. Sep. Purif. Technol. 2014;132:505-512.

47. Ghosh G, Bhattacharya PK. Hexavalent chromium ion removal through micellar enhanced ultrafiltration. Chem. Eng. J. 2006;119:45-53.

48. Rahmanian B, Pakizeh M, Maskooki A. Optimization of lead removal from aqueous solution by micellar-enhanced ultrafiltration process using Box-Behnken design. Korean J. Chem. Eng. 2012;29:804-805.

49. Chhatre AJ, Marathe KV. Dynamic analysis and optimization of surfactant dosage in micellar enhanced ultrafiltration of nickel from aqueous streams. Sep. Sci. Technol. 2006;41:2755-2770.

50. Danis U, Aydiner C. Investigation of process performance and fouling mechanisms in micellar-enhanced ultrafiltration of nickel-contaminated waters. J. Hazard. Mater. 2009;162:577-587.

51. Landaburu-Aguirre J, García V, Pongrácz E, Keiski RL. The removal of zinc from synthetic wastewaters by micellar- enhanced ultrafiltration: Statistical design of experiments. Desalination 2009;240:262-269.

52. Lee SH, Shrestha S. International biodeterioration \& biodegradation application of micellar enhanced ultra filtration (MEUF) process for zinc(II) removal in synthetic wastewater : Kinetics and two-parameter isotherm models. Int. Biodeterior. Biodegrad. 2014;95:241-250.

53. Zhang Z, Zeng G, Huang J, Fang Y, Xu K. Removal of zinc ions from aqueous solution using micellar- enhanced ultrafiltration at low surfactant concentrations. Afr. J. Online 2007;33:129136.

54. Bunting JW, Thong KM. Stability constants for some 1:1 metal-carboxylate complexes. Can. J. Chem. 1970;48:1654-1656.

55. Karate VD, Marathe KV. Simultaneous removal of nickel and cobalt from aqueous stream by cross flow micellar enhanced ultrafiltration. J. Hazard. Mater. 2008;157:464-471.

56. Manchalwar SM, Anthati VA, Marathe KV. Simulation of micellar enhanced ultrafiltration by multiple solute model. J. Hazard. Mater. 2010;184:485-492.

57. Channarong B, Lee SH, Bade R, Shipin OV. Simultaneous removal of nickel and zinc from aqueous solution by micellar-enhanced ultrafiltration and activated carbon fiber hybrid process. Desalination 2010;262:221-227.

58. Scamehorn JF, Christian SD, El-Sayed DA, Uchiyama H, Younis SS. Removal of divalent metal cations and their mixtures from aqueous streams using micellar-enhanced ultrafiltration. Sep. Sci. Technol. 1994;29:809-830.

59. Kim H, Baek K, Kim B, Shin H, Yang J. Removal characteristics of metal cations and their mixtures using micellar-enhanced ultrafiltration. Korean J. Chem. Eng. 2008;25:253-258.

60. Sohan S, Lee SH, Lee TK. Micellar enhanced ultrafiltration (MEUF): Activated carbon fiber (ACF) hybrid process using low surfactant concentration for zinc(II) removal from syn- thetic wastewater. Desalin. Water Treat. 2015;54:929-943.

61. Juang RS, Xu YY, Chen CL. Separation and removal of metal ions from dilute solutions using micellar-enhanced ultrafiltration. J. Membr. Sci. 2003;218:257-267.

62. Ferella F, Prisciandaro M, De Michelis I, Veglio F. Removal of heavy metals by surfactant-enhanced ultrafiltration from wastewaters. Desalination 2007;207:125-133

63. Nguyen LAT, Schwarze M, Schomäcker R. Adsorption of non-ionic surfactant from aqueous solution onto various ultrafiltration membranes. J. Membr. Sci. 2015;493:120-133.

64. Bade R, Lee SH. A review of studies on micellar enhanced ultrafiltration for heavy metals removal from wastewater. $J$. Water Sustain. 2011;1:85-102.

65. Baek K, Yang JW. Micellar-enhanced ultrafiltration of chromate and nitrate: Binding competition between chromate and nitrate. Desalination 2004;167:111-118.

66. Baek K, Yang JW. Cross-flow micellar-enhanced ultrafiltration for removal of nitrate and chromate: Competitive binding. J. Hazard. Mater. 2004;108:119-123.

67. Rafique RF, Lee S. Micellar enhanced ultrafiltration (MEUF) and activated carbon fiber (ACF) hybrid processes for the removal of cadmium from an aqueous solution. Korean Chem. Eng. Res. 2014;52:775-780.

68. Gecol H, Ergican E, Fuchs A. Molecular level separation of arsenic(V) from water using cationic surfactant micelles and ultrafiltration membrane. J. Membr. Sci. 2004;241:105-119.

69. Rafique RF, Chowdhury ZZ, Moon J, Lee S. Application of micellar enhanced ultrafiltration (MEUF) and activated carbon fiber (ACF) hybrid processes for the removal of nickel from an aqueous solution. Int. J. Innov. Eng. Technol. 2018;10: 112-120.

70. Purkait MK, DasGupta S, De S. Resistance in series model for micellar enhanced ultrafiltration of eosin dye. J. Colloid Interface Sci. 2004;270:496-506.

71. Mizoguchi K, Fukui K, Yanagishita H, Nakane T, Nakata T. Ultrafiltration behavior of a new type of non-ionic surfactant around the CMC. J. Membr. Sci. 2002;208:285-288.

72. Void MJ. Micellization process with emphasis on premicelles. Langmuir 1992;8:1082-1085.

73. Baek K, Kim BK, Yang JW. Application of micellar enhanced ultrafiltration for nutrients removal. Desalination 2003;156: 137-144

74. Goddard ED. Surfactants and interfacial phenomena: by Milton J. Rosen, 2nd ed. New York: John Wiley \& Sons; 1989 (book review). Colloid. Surf. 1989;40:347.

75. Akita S, Yang L, Takeuchi H. Micellar-enhanced ultrafiltration of gold(III) with nonionic surfactant. J. Membr. Sci. 1997;133:189-194.

76. Liu CK, Li CW. Simultaneous recovery of copper and surfactant by an electrolytic process from synthetic solution prepared to simulate a concentrate waste stream of a micellar-enhanced ultrafiltration process. Desalination 2004;169:185-192.

77. Huang J-h, Zeng G-m, Qu Y-h, Zhang Z. Adsorption characteristics of zinc ions on sodium dodecyl sulfate in process of micellar-enhanced ultrafiltration. Trans. Nonferrous Met. Soc. China 2007;17:1112-1117.

78. Chaudhari RR, Marathe KV. Separation of dissolved phenolics 
from aqueous waste stream using micellar enhanced ultrafiltration. Sep. Sci. Technol. 2010;45:1033-1041.

79. Trivunac K, Stevanovic S. Removal of heavy metal ions from water by complexation-assisted ultrafiltration. Chemosphere 2006;64:486-491.

80. Zeng GM, Xu K, Huang JH, Li X, Fang YY, Qu YH. Micellar enhanced ultrafiltration of phenol in synthetic wastewater using polysulfone spiral membrane. J. Membr. Sci. 2008;310:149-160.

81. Rosen MJ, Kunjappu JT. Surfactants and interfacial phenomena. 4th ed. John Wiley \& Sons; 2012.

82. Baek K, Yang JW. Effect of valences on removal of anionic pollutants using micellar-enhanced ultrafiltration. Desalination 2004;167:119-125.

83. Liu CK, Li CW. Combined electrolysis and micellar enhanced ultrafiltration (MEUF) process for metal removal. Sep. Purif. Technol. 2005;43:25-31.

84. Kowalska I, Majewska-Nowak K, Kabsch-Korbutowicz M. Influence of temperature on anionic surface active agent removal from a water solution by ultrafiltration. Desalination 2006;198:124-131.

85. Purkait MK, DasGupta S, De S. Performance of TX-100 and TX-114 for the separation of chrysoidine dye using cloud point extraction. J. Hazard. Mater. 2006;137:827-835.

86. Bhat MA, Dar AA, Amin A, Rashid PI. Temperature dependence of transport and equilibrium properties of alkylpyridinium surfactants in aqueous solutions. J. Chem. Therm. 2007;39:1500-1507.

87. Zaghbani N, Hafiane A, Dhahbi M. Removal of Eriochrome Blue Black R from wastewater using micellar-enhanced ultrafiltration. J. Hazard. Mater. 2009;168:1417-1421.

88. Rosen MJ. Surfactants and interfacial phenomena. Wiley \& Sons; 2004.

89. Gwicana S, Vorster N, Jacobs E. The use of a cationic surfactant for micellar-enhanced ultrafiltration of platinum group metal anions. Desalination 2006;199:504-506.

90. Cañizares P, Pérez Á, Camarillo R, Llanos J, López ML. Selective separation of $\mathrm{Pb}$ from hard water by a semi-continuous polymer-enhanced ultrafiltration process (PEUF). Desalination 2007;206:602-613.

91. Hankins N, Hilal N, Ogunbiyi OO, Azzopardi B. Inverted polarity micellar enhanced ultrafiltration for the treatment of heavy metal polluted wastewater. Desalination 2005;185:185-202.

92. Talens-alesson FI. Behaviour of SDS micelles bound to mixtures of divalent and trivalent cations during ultrafiltration. Colloids Surf. A Physicochem. Eng. Asp. 2007;299:169-179.

93. Vieira M, Tavares CR, Bergamasco R, Petrus JCC. Application of ultrafiltration-complexation process for metal removal from pulp and paper industry wastewater. J. Membr. Sci. 2001;194:273-276.

94. Biver T, Paoletti C, Secco F, Venturini M. Extraction, separation and recovery of palladium and platinum by a kinetic method combined with ultrafiltration. Colloids Surf. A Physicochem. Eng. Asp. 2014;441:466-473.

95. Bautista-toledo I. Removal of the surfactant sodium dodecylbenzenesulphonate from water by simultaneous use of ozone and powdered activated carbon: Comparison with systems based on $\mathrm{O}_{3}$ and $\mathrm{O}_{3} / \mathrm{H}_{2} \mathrm{O}_{2}$. Water Res. 2006;40:1717-1725.

96. Basar CA, Aydiner C, Kara S, Keskinler B. Removal of $\mathrm{CrO}_{4}$ anions from waters using surfactant enhanced hybrid PAC/MF process. Sep. Purif. Technol. 2006;48:270-280.

97. Landdaburu-Aguirre J. Micellar-enhanced ultrafiltration for the removal of heavy metals from phosphorous-rich wastewaters : From end-of-pipe to clean technology [dissertation]. Oulu: Univ. of Oulu; 2012.

98. Puasa SW, Ruzitah MS, Sharifah ASAK. An overview of micellar-enhanced ultrafiltration in wastewater treatment process. In: Proceedings of International Conference on Environment and Industrial Innovation (ICEII 2011), 2011. 